\title{
Enhancement in Growth and Yield of Ashwagandha (Withania Somnifera (L.) Dunal) by Counteracting Effect of Infrared Supplemented with Ultraviolet-B Radiation
}

\author{
Manju Nagar ${ }^{1}$, Surchi Tyagi ${ }^{2}$, Ashwani Kumar Goyal ${ }^{3}$ \\ ${ }^{1,2}$ Department of Botany, M.M.H. College, Ghaziabad, C.C.S University, Meerut, Uttar Pradesh, India \\ ${ }^{3}$ Joint Sectary Higher Education, U.P Civil Secretariat, Lucknow (U.P.), India
}

\begin{abstract}
Ashwagandha (Withania somnifera(L.) Dunal), member of family Solanaceae, is one of the most important medicinal plants required in allopathic, ayuredic and unani system of medicines. The roots of ashwagandha possess health maintenance and restoration properties, similar to ginseng roots, hence known as Indian ginseng. The leaf is useful for inflammation, swelling and conjunctivitis. Bark decoction helps in asthama. Its extract has powerful protective effects on nervous system. Therefore ashwagandha is demanding in pharmaceutical market, so production is less than its consumption, therefore included in critically endangered species in Red Data book. Ozone depletion resulted in increased $U V-B$ radiation, have desruptive effects on growth and development of flora but for short period at regular intervals it is beneficial, and IR radiation enhance the yield in plants. Since the plant growth is dynamic complex process and the solar radiation at different altitudes alter the growth, development and biosynthesis in plants. So looking at the view of high demand and sustainable use of natural wealth. Ashwagandha has much scope for wide cultivation. Since information on these aspects of ashwagandha is meagre. Therefore in present investigation counteracting effects of infrared and UV-B radiation on ashwagandha was undertaken to evaluate growth and yield of crop.
\end{abstract}

Keywords: IR, UV-B, growth, yield

\section{Introduction}

Stratospheric ozone layer depletion is one of the most important component of global climate change and results in global warming. UV-B radiation, a part of the sunlight, has wavelength ranges from $280-320 \mathrm{~nm}$ and infrared (IR) radiation lies in 680-700nm light spectrum. Ozone depletion has prompted recent efforts in assessing the potential damage to vegetation due to enhanced levels of ultraviolet-B radiation (World Meteorological Organization,1989; Grant,1990; Bornman,1991; Nunez et. al.,1994; Caldwell et. al.,1998; Mandronich et. al.,1998). UV-B irradiance have direct as well as indirect impact on plants, as damages detected in many cell components including membranes, proteins DNA, inconjunction with alteration on plant growth, morphology, physiological and biochemical processes (Jansen et. al., 1998). Plant species and varieties differ greatly in their response, with the response generally dependent on the ratio of UV-B to UV-A (Teramura,1983; Tevini and Teramura,1989; Middleton and Teramura,1994).Some species show sensitivity to present levels of UV-B irradiance (Bongenrieder and Klein,1982) while others are apparently unaffected by rather massive UV-B enhancements (Becwar et. al., 1982). One third to one half of all plant species tested are deleteriously affected by above ambient UV-B levels (Sullivan, 1992). In contrast to detailed studies of UV-B radiation responses little is known about the biological effects of IR radiation, since infrared radiation showed positive effects in cosmetic, wellness purposes and dermatology (Lee et. al.,2006) but very meagre information about effects on plants physiological aspects are available. In the present scenario the use of herbal and ayurvedic medicines are increasing at a very rapid rate because they are accessible, affordable, and culturally appropriate sources of primary health care for more than $80 \%$ of Asia's population (WHO). India exports herbal products and medicine to the tune of Rs550 crores annually. Out of 80,000 tonnes of medicinal plants imported by western countries, India tops the list of exporters to USA and Europe with a share of over 10,000 tonnes. The value of trade in medicinal plants is about Rs 5,000 crores while the world trade is about US \$ 62 billions. A survey indicated the use of herbal medicines will reach to the tune of US $\$ 5$ trillions during 2050. Currently, the ayurvedic and herbal products turnover is estimated to be Rs 25,000 crores. Withania somnifera (L.)Dunal, is also an important medicinal plant, belongs to family Solanaceae, popularly known as Ashwagandha or Wintercherry (Andallu and Radhika,2000). It is described as herbal tonic and health food in vedas and considered as 'Indian Ginseng' in traditional Indian system of medicine (Singh et. al.,2001). It is generally used as anti-inflammatory, anti-cancer, antistress and immunomodulator, adaptogenic, central nervous system, endocrine and cardiovascular activities respectively (Bhattacharya et. al.,1997a; Mohanty et. al.,2004; Ahmed et. al.,2005). Therefore from medicinal as well as economical point of view ashwagandha's overproduction will be a boon for the future scenario of India. Due to its heavy consumption in pharmacology, ashwagandha is underproducted crop and included in endangered species in Red-Data Book. So higher productivity with superior quality of Ashwagandha is essential. The present study therefore aimed to highlight the Influence of IR radiation counterfed with supplemented UV-B radiation to increase the growth and yield of Ashwagandha. 


\section{International Journal of Science and Research (IJSR) \\ ISSN (Online): 2319-7064}

Index Copernicus Value (2013): 6.14 | Impact Factor (2014): 5.611

\section{Material and Methods}

Seeds of Ashwagandha were collected from IARI (Indian Agricultural Research Institute), New Delhi, treated with $0.1 \% \mathrm{HgCl}_{2}$ (Mercuric Chloride), washed with fresh water and finally with distilled water, then sown in field in five different plots. The crop was grown under UV-B-B and IR radiation separately and countered with each other i.e. Control, IR, UV-B, IR+UV-B, UV-B+IR respectively treatment was given at regular intervals of 15 days from germination till maturity. For growth and productivity method adopted by Kumar (1981) and Singh et. al., (1975) were adopted respectively.

\section{Result and Discussion}

Plants are affected by solar radiation differently on different regions of earth i.e. from temperate to tropical regions and from species to species. The results revealed that maximum promoted (1.435 times of control ) root length observed with UV-B treatment after that 1.076 times growth observed under IR treatment as of control, while declined(0.98 times of control) root length observed under IR+UV-B-B and 0.89 times of control observed under UV-B+IR treatment as shown in table1 and fig.1. This shows that marked increase observed under UV-B and IR treatment separately for $1 \mathrm{~h}$ each. The result is consistent with Kumar Ambrish(1992), studied that for shorter duration UV-B is promoting in legume crops and Geeta et al.,(2014) in Capsicum annum showed positive effects of UV-B radiation on different plant parts.

Fresh weight of root as shown in table1 and fig. 3 found inclined by $224 \%, 146 \%$ and $113 \%$ under UV-B+IR, IR+UV$\mathrm{B}$ and IR treatments respectively as of control but marked decline of $24 \%$ with control observed under UV-B treatment. Dry weight of root was promoted maximum by $274 \%$ in UV-B+IR treatment and $174 \%$ and $118 \%$ observed under IR+UV-B and IR treatment but decline of $76.84 \%$ observed in UV-B treatment, shown in table1 and fig4. These were in accordance with Pal et.al., (1995) in Vigna radiata L. Wilczek but Zavala and Botto(2002) studied the increased biomass in Raphanus sativus, since radish is a kharif crop. Muleo and Morini (2008) observed the maximum fresh and dry weight in M9 apple under red light treatment.

A perusal of our results for stem growth parameters viz. length, fresh weight and dry weight suggests that there is maximum growth under UV-B+IR treatment by $177.34 \%$, $256 \%$ and $236.36 \%$ respectively as compared with control as shown in table1 and fig1, 4 and 5. There is also a marked increase in other treatments as compared to control. Length of shoot increased under UV-B, IR+UV-B and IR treatment as $176.87 \%, 176.4 \%$ and $154.9 \%$ respectively as shown in table1 and fig. 1 . Table1 and fig3 and 4 showed that the fresh weight and dry weight with IR+UV-B treatment increased by $223.67 \%$ and $181.82 \%$ respectively. Fresh weight and dry weight enhanced by $191.12 \%$ and $116.88 \%$ with UV-B treatment and by $233.14 \%$ and $154.55 \%$ under IR treatment. The above result were consistent with Al-Oudat et.al.,(1998) and Muleo and Morini(2008).

Results obtained for leaf shows that maximum promotory effect shown in UV-B+IR treatment except for leaf area index. Table 1 and fig 2,3 and 4 showed number of leaves, fresh weight and dry weight increased by $149 \%, 269.41 \%$ and $224.12 \%$ respectively. Under IR treatment promotory effect in number of leaves by $166.92 \%$ showed, after that under UV-B+IR, UV-B and IR+UV-B showed 149\%, $146.4 \%$ and $135.11 \%$ respectively as compared with control. Growth in fresh and dry weight observed higher in UV$\mathrm{B}+\mathrm{IR}$ followed by IR+UV-B, UV-B and finally by IR as (269.41\%and 224.72\%), (200.86\% and $156.93 \%)$, (187.4\% and $104.87 \%)$ and $(166.67 \%$ and $115.73 \%)$ respectively. The leaf area index showed in table1 and fig 5 declined with all the four treatments. Maximum decline studied under UVB+IR treatment by $56.98 \%$ followed by IR+UV-B, IR and UV-B as $71.8 \%, 85.8 \%$ and $91.89 \%$. Saebo et.al., (1995) and Pal et.al., (1998) in Mustard cultivar are in favor of above result.

Table1 and fig. 2, 3 and 4 showed in control flowering stops at the maturity of the crop and decline in fruit growth pattern as compared with control. Fruit under UV-B and IR treatment were diminished after 90 days but UV-B+IR and IR+UV-B showed declination by $(34.79 \%, 40 \%$ and $41.17 \%)$ and $(8.8 \%, 7.43 \%$ and $8.2 \%)$ respectively on maturity.

Table 1: Counteracting effect of Infra-Red radiation supplemented with UV-B radiation on growth of Withania somnifera (L.) Dunal.

\begin{tabular}{|c|c|c|c|c|c|c|}
\hline Treatment & Parameter & Root & Stem & Leaf & Flower & Fruit \\
\hline Control & Length, cm/ No. & 15.8 & 42.8 & 133 & - & 30.67 \\
\hline T1 & Fw, g & 7.8 & 16.9 & 16.38 & - & 3.5 \\
\hline & Dw,g & 1.9 & 3.85 & 2.67 & - & 0.61 \\
\hline & Leaf area index & & & 30.36 & & \\
\hline & & & & & & \\
\hline IR & Length, cm/No. & 17 & 66.3 & 222 & 33.67 & 18 \\
\hline T2 & Fw,g & 8.8 & 39.4 & 27.3 & 1.33 & 1.5 \\
\hline & Dw,g & 2.25 & 5.95 & 3.09 & 0.27 & 0.14 \\
\hline & Leaf area index & & & 26.05 & & \\
\hline & & & & & & \\
\hline UV-B & Length, cm/No. & 22.67 & 75.5 & 194.67 & 11.3 & 14 \\
\hline T3 & Fw,g & 5.9 & 32.3 & 30.7 & 0.028 & 1.5 \\
\hline & Dw,g & 1.46 & 4.5 & 2.8 & 0.003 & 0.11 \\
\hline & Leaf area index & & & 27.9 & & \\
\hline & & & & & & \\
\hline IR+UV-B & Length, cm/No. & 15.5 & 75.5 & 179.7 & 41.3 & 2.7 \\
\hline T4 & Fw,g & 11.4 & 37.8 & 32.9 & 0.35 & 0.26 \\
\hline & Dw,g & 3.3 & 7 & 4.19 & 0.072 & 0.05 \\
\hline & Leaf area index & & & 21.8 & & \\
\hline & & & & & & \\
\hline UV-B+IR & Length, cm/No. & 14.1 & 75.9 & 198.3 & 64 & 10.67 \\
\hline T5 & Fw,g & 17.48 & 43.32 & 44.13 & 1.62 & 1.4 \\
\hline & Dw,g & 5.2 & 9.1 & 6 & 0.03 & 0.247 \\
\hline & Leaf area index & & & 17.3 & & \\
\hline
\end{tabular}


International Journal of Science and Research (IJSR)

ISSN (Online): 2319-7064

Index Copernicus Value (2013): 6.14 | Impact Factor (2014): 5.611

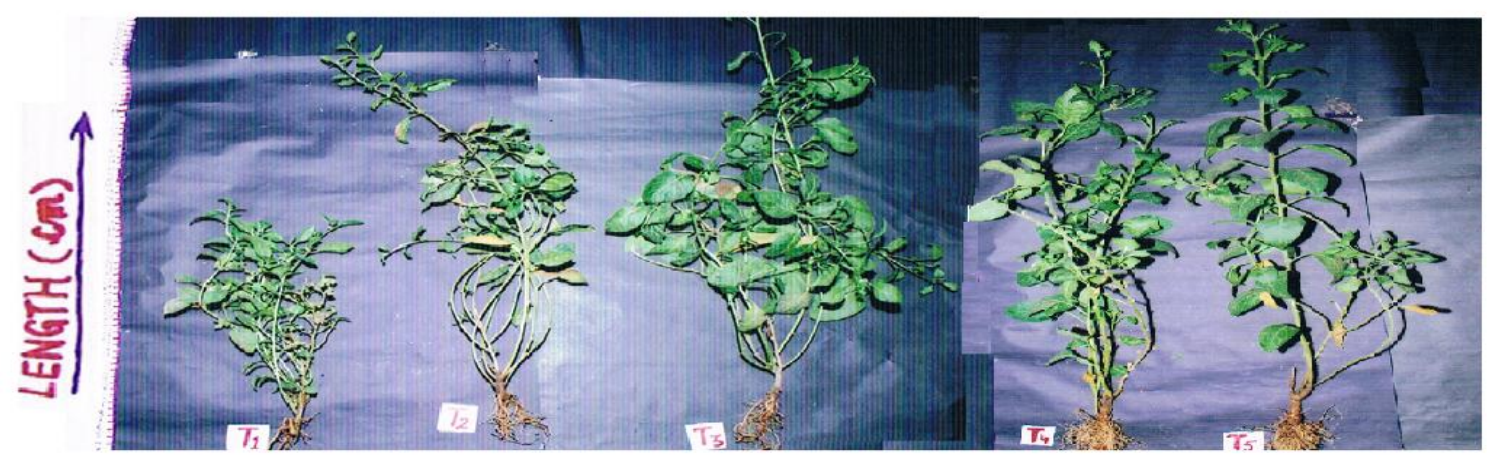

Diag. Counteracting effect of IR and UV-B radiation on full plant length

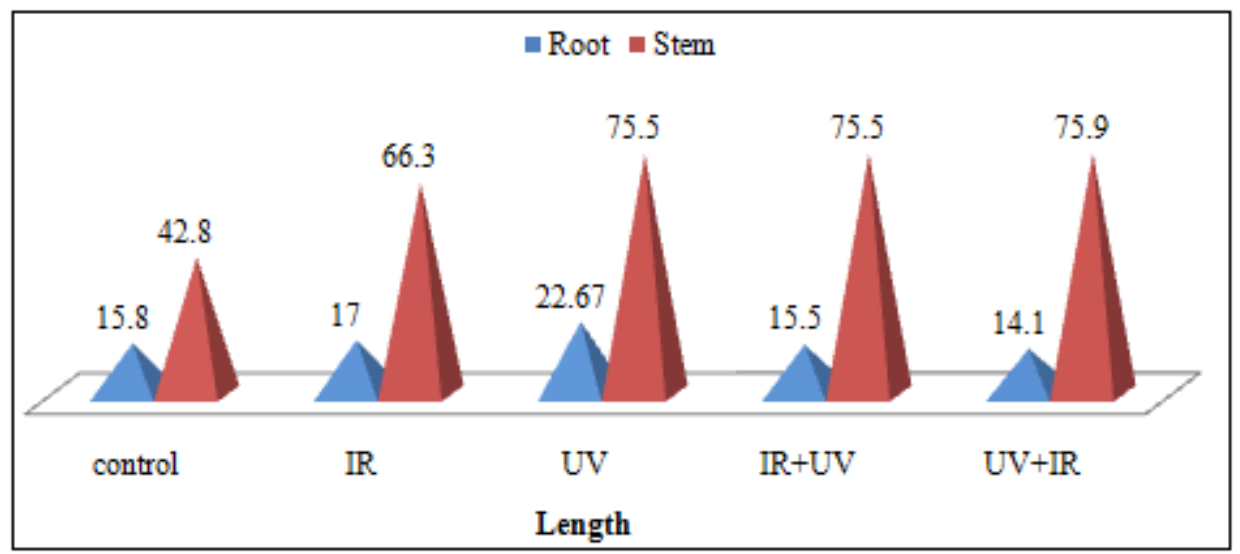

Fig.1 Counteracting effect of UV-B and IR radiation on root and shoot length of Withania somnifera (L.) Dunal

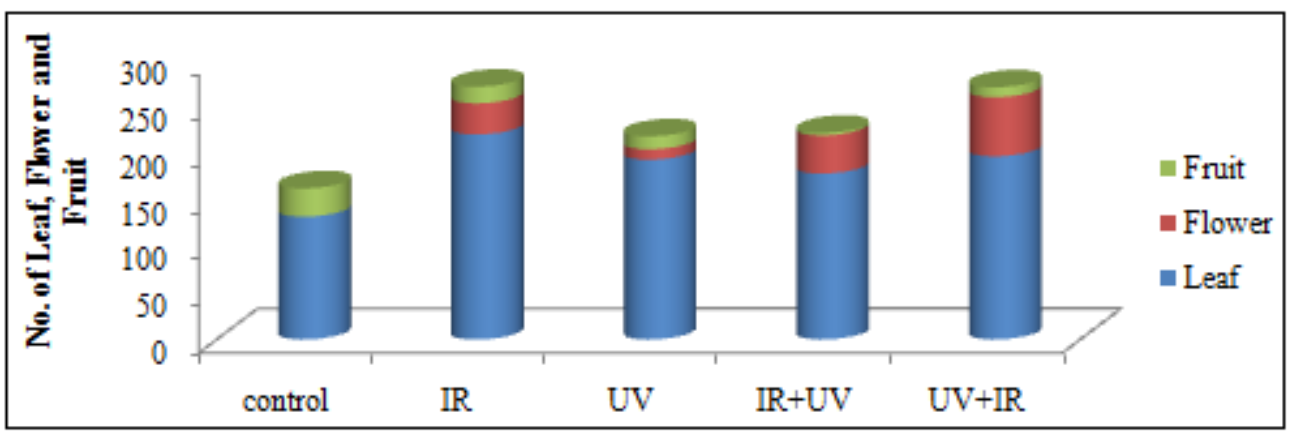

Figure 2: Counteracting effect of UV-B and IR radiation on number of leaf, flower and fruit of Withania somnifera (L.) Dunal

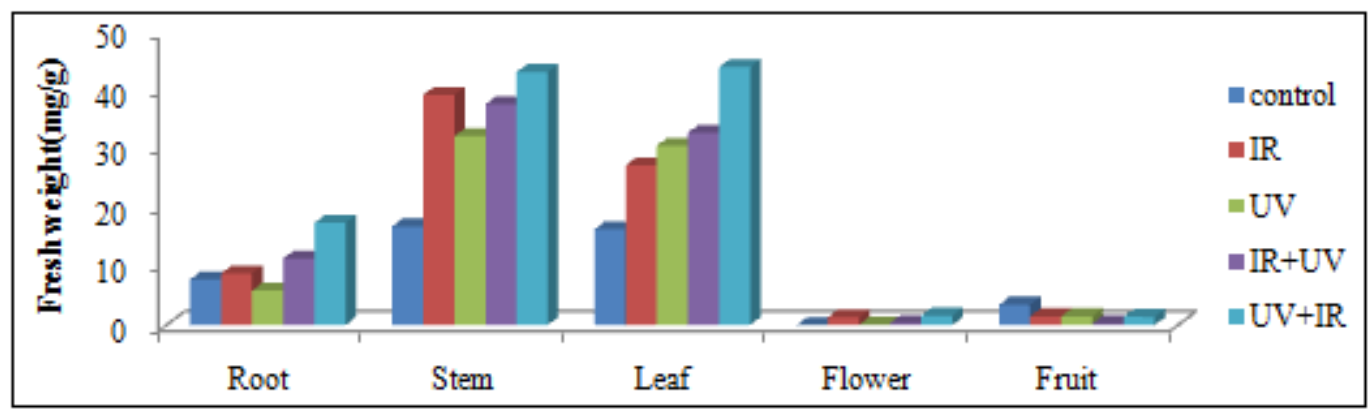

Figure 3: Counteracting effect of UV-B and IR radiation on fresh weight ( $\mathrm{mg} / \mathrm{g})$ of root, stem, leaf, flower and fruit of Withania somnifera (L.) Dunal 


\section{International Journal of Science and Research (IJSR) \\ ISSN (Online): 2319-7064}

Index Copernicus Value (2013): 6.14 | Impact Factor (2014): 5.611

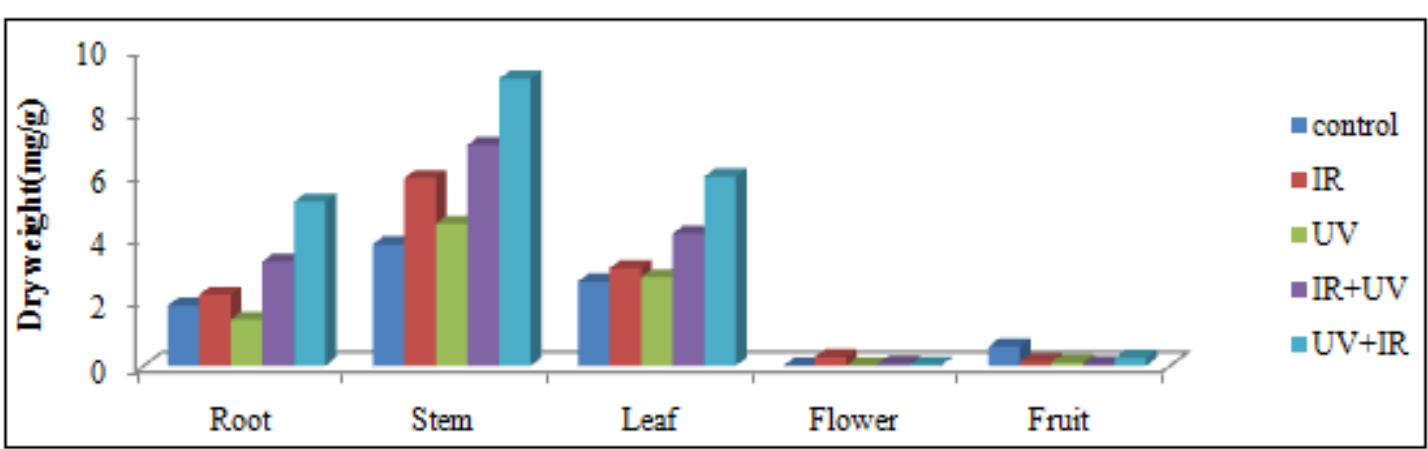

Figure 4: Counteracting effect of UV-B and IR radiation on dry weight $(\mathrm{mg} / \mathrm{g})$ of root, stem, leaf, flower and fruit of Withania somnifera $(\mathrm{L}$.$) Dunal$

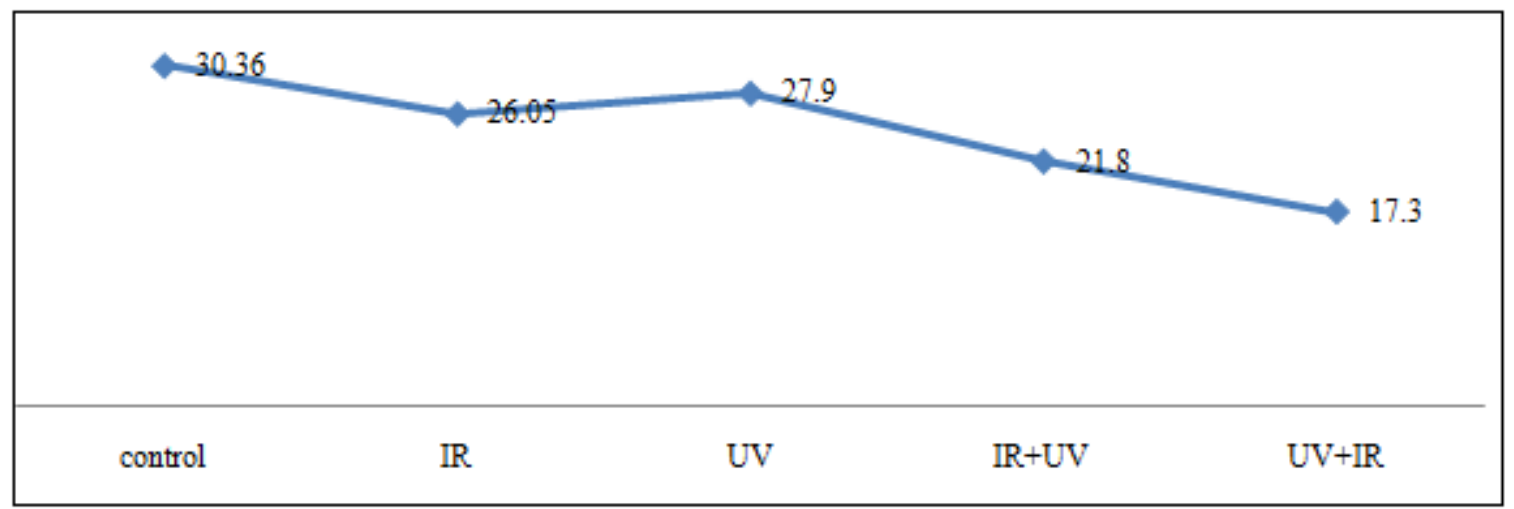

Figure 5: Counteracting effect of IR and UV-B on leaf area index of Withania somnifera (L.) Dunal

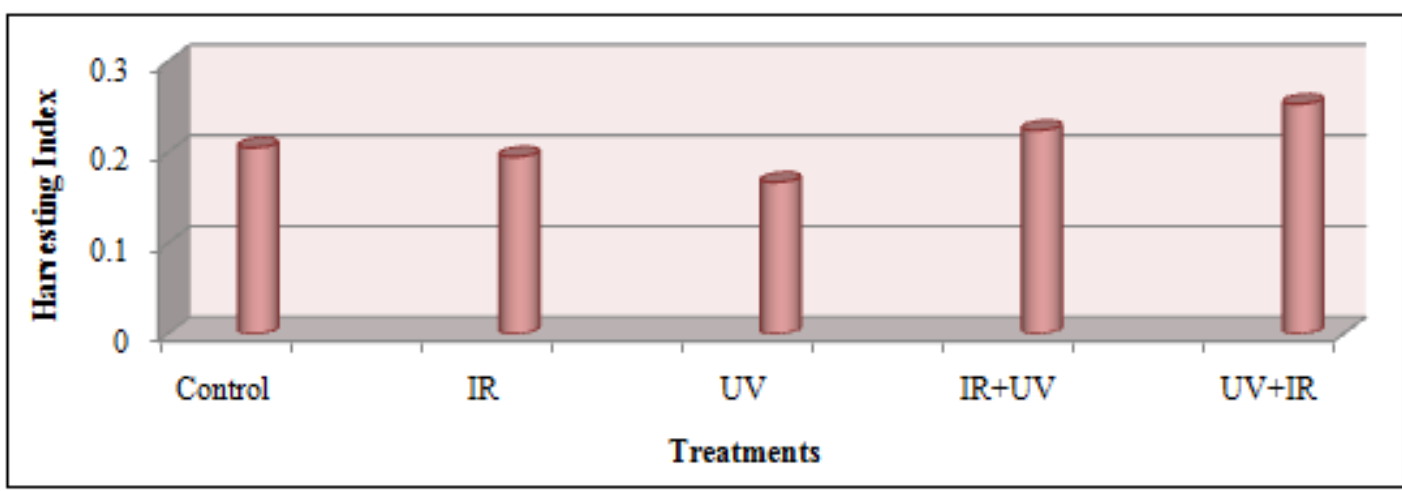

Figure 5: Counteracting effect of UV-B and IR radiation on Harvesting index of Withania somnifera (L.) Dunal

Table 2: Counteracting effect of Infrared radiation supplemented with UV-B radiation on yield attributes of ashwagandha (Withania somnifera (L.) Dunal)

\begin{tabular}{|c|c|c|c|}
\hline \multirow{2}{*}{ Treatment } & \multirow{2}{*}{ Total } & Biomass $($ g/plant $)$ & Harvesting \\
\cline { 3 - 4 } & & Root & Index \\
\hline Control & 9.27 & 1.9 & 0.205 \\
\hline IR & 11.56 & 2.25 & 0.195 \\
\hline UV-B & 8.763 & 1.46 & 0.167 \\
\hline IR+UV-B & 14.712 & 3.3 & 0.224 \\
\hline UV-B+IR & 20.577 & 5.2 & 0.253 \\
\hline
\end{tabular}

The yield of a plant is determined by the economically important part of the plant. In ashwagandha the economically important parts are roots. Harvesting index is the indicator of the compartmental transfer of biomass. Crop harvesting index was affected in all the treatments. Harvesting index as shown in table 2 promoted maximum under UV-B+IR treatment by $123.42 \%$ and by $109.27 \%$ under IR+UV-B treatment as with control but decline by $95.12 \%$ and $81.46 \%$ with IR and UV-B treatment was studied with control. The present results were supported by
Gao et.al., (2003) in cotton (Gossypium sps). Therefore the counteracting treatments of supplemental UV-B and IR radiation are beneficial from growth and yield point of view as compared to the separate treatments of UV-B and IR radiation.

\section{Conclusion}

As we see that counteracting effect of infrared radiation and supplemental ultraviolet-B radiation increase the growth and yield of the Withania somnifera (L.) Dunal. Therefore it will help India to strong the economy as well as health of poor and ultimately act as boon for the future of India.

\section{Acknowledgement}

The authors would be like to thanks the faculty of Department of Botany M.M.H College Ghaziabad for their technical support and providing the necessary laboratory facilities. 


\section{International Journal of Science and Research (IJSR) \\ ISSN (Online): 2319-7064 \\ Index Copernicus Value (2013): 6.14 | Impact Factor (2014): 5.611}

\section{References}

[1] Ahmad, M., Saleem, A.S. Ahmad, M.A. Ansari, S. Yousuf and Hoda, M.N. (2005). Neuroprotective effects of Withania somnifera on 6-hydroxydopamine induced Parkinsonism in rats. Hum. \& Exp. Toxicol., 24:137-147.

[2] Al-Oudat M., Baydoun S. A., Mohammad A.,(1998). Effects of enhanced UV-B-B on growth and yield of two Syrian crops wheat (Triticum durumvar. Horani) and broad beans (Vicia faba) under field conditions. Environ Exp Bot 40: 11-16.

[3] Andallu, B and B. Radhika, (2000). Hypoglycemic diuretic and hypocholesterolemic effect of winter cherry (Withania somnifera Dunal) root. Ind. J. of Exp. Bio., 38:607-609.

[4] Becwar, M.R., Morre III, F.D, Bureke, M.J., (1982). Effects of depletion and enhancement of ultraviolet-B $(280-315 \mathrm{~nm})$ radiation on plants grown at $3000 \mathrm{~m}$ elevation. J. Am. Soc. Hort. Sci. 107: 771-779.

[5] Bhattacharya, S.K., Satyan, K.S. and Chakrabarti, A. (1997a). Effect of Trasina, an Ayurvedic herbal formulation, on pancreatic islet superoxide dismutase activity in hyperglycaemic rats. Ind. J. of Exp. Bio., 35:297-299.

[6] Bogenrieder, A., Klein, R., (1982). Does solar UV-B influence the competitive relationship of higher plants? In: The role of Solar Ultraviolet Radiation in Marine Ecosystems. Plenum Press, New York, pp.641-649.

[7] Bornmann J.F., (1991). UV-B radiation as an environmental stress in plants. J. Photochem. Photobiol. B: Biol. 8: 337-342.

[8] Caldwell, M.M., Bjorn, L.O., Bornman, J.F., Flint,S.D., Kulandaivelu, G., Teramura, A.H., Tevini,M., (1998). Effect of increased solar ultraviolet radiation on Terrestrial ecosystems. J. Photochem. Photobiol. B: Biol.46 (1-3), 40-52.

[9] Gao, W., Zheng, Y.,Slusser J.R and Heisler, G.M., (2003). Impact of enhanced ultraviolet- B radiation on cotton growth, development, yield, and qualities under field conditions. Agricultural and forest Meteorology. 120: 241-248.

[10] Geeta., Sarita and Goyal., A.K. (2014): Response of UV-B Radiation on Germination Percentage, Growth Pattern and Chlorophyll content at seedling stage of Capscicum annum L. Int J. of Scientific and Research Publications. 4 (8): 1-5.

[11] Grant, R.H., (1990). UV-B radiation with agricultural plant canopies. In: Proceedings of the $\mathbf{1 2}^{\text {th }}$ International Congress of Biometeorology, Vienna, Austria. International Society of Biometereology,p.7(Abstracts).

[12] Jansen, M. A. K., Gaba, V. and Greenberg, B. M. (1998). Higher plants and UV-B radiation: balancing damage, repair and acclimation. Trends Plant Sci. 3:131-135.

[13] Kumar A., (1992). Effect of supplemental UV-B radiation on growth and composition of certain legume crops. Ph. D. Thesis. H.N.B. University, Garhwal..

[14] Kumar, A. (1981): Effects of growth regulators on growth pattern,productivity, mineral cycling and energy budget of ground nut (Arachis hypogea L.). Phd.Thesis. Meerut Univ., Meerut, U.P. India.

[15] Lee, J.H., Roh, M.R. and Lee, K.H.,(2006). Effects of infrared radiation on skin photo- Aging and Pigmentation. Yonsei Med J. 47(4): 485-490.

[16] Mandronich, S., McKenzie, R.L., Bjorn, L., Caldwell, M.M., (1998). Changes in biologically active ultraviolet radiation reaching the Earth's surface. J. Photochem. Photobiol. B:Biol.46 (1-3): 5-19.

[17] Middleton, E.M., Teramura, A.H., (1994). Understanding photosynthesis, pigment and growth response induced by UV-B-B and UV-B-A irradiance. J. Photochem. Photobiol. 60: 38-45.

[18] Mohanty, I., D.S. Arya, A. Dinda, K.K. Talwar, S. Joshi and S.K. Gupta. (2004). Mechanisms of cardioprotectiveeffect of Withania somnifera in experimentally induced myocardial infarction. Basic and Clinical Pharmacology and Toxicology, 94:184190.

[19] Muleo, R., Morini, S.,(2008). Physiological dissection of blue and red light regulation of apical dominance and branching in M9 apple root stock growing in vitro. J. of Plant Physiol.165:1838-1846.

[20] Nunez, M., Forgan, B., Roy, C., (1994). Estimating ultraviolet radiation at the earth's surface. Int.j.Biometereol. 38, 5-17.

[21] Pal, M., Jain, V. and Sengupta, U.K.,(1998). Influence of enhanced UV-B radiation on Mustard: Cultivar response. Indian J. Plant Physiol., 3(3): 188-193.

[22] Pal, M., Sharma, A., Sengupta, U.K.,(1995). Effect on germination and seedling growth in mungbean (Vigna radiate L. WILCZEK). Indian J. Plant Physiol., 38(4): 293-297.

[23] Saebo, A., Krekling, T. and Appelgren, M., (1995). Light quality affects photosynthesis and leaf anatomy of birch plantlets in vitro. Plant Cell Tissue Organ Cult. 51:187-93.

[24] Singh J.S., Lauenroth W.K. and Steinhorst R.K. (1975):Review and assessment of various techniques for estimating net aerial primary production in grassland from harvest data. Bot.Rev.41: 181-232.

[25] Singh, B., A.K. Saxena, K.K. Chandan, D.K. Gupta, K.K. Bhutani and K.K. Anand. (2001). Adaptogenic activity of a novel withanolide- free aqueous fraction from the roots of Withania somnifera Dunal. Phytotherapy Research, 15:311-318.

[26] Sullivan, J., (1992). Effects on Terrestrial Plants. UVB Monitoring Workshop: A Review of the Science and Status of Measuring and Monitoring Programs, Washington, DC. Science and Policy Associates Inc., Washington, DC.

[27] Teramura A. H. (1983). Effects of ultraviolet radiation on growth and yield of crop plants. Physiol. Plant., 58: 415-427.

[28] Tevini, M. and Teramura, A.H.(1989). UV-B effects on terrestrial plants. Photochem Photobiol. 50:479 487.

[29] World Metereological Organization,(1989). Scientific assessment of Stratospheric Ozone. Global Ozone Research and Monitoring Project, Rpt. No. 20. Geneva, Switzerland.

[30] Zavala, J.A. and Botto, J.F., (2002). Impact of solar UV-B-B radiation on seedling emergence, chlorophyll 


\section{International Journal of Science and Research (IJSR) \\ ISSN (Online): 2319-7064}

Index Copernicus Value (2013): 6.14 | Impact Factor (2014): 5.611

fluorescence, and growth and yield of radish(Raphanus sativus).Funct. Plant Biol.,29: 797-804.

\section{Author Profile}

Manju Nagar, Doctoral Candidate, Department of Botany, M.M.H. College, Ghaziabad, C.C.S University, Meerut, Uttar Pradesh, India.

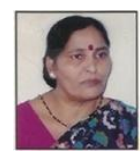

Dr. Suruchi Tyagi, Associate Professor, Msc, Mphil, Ph.D, F.B.S, Head of Department Botany, M.M.H. College, Ghaziabad, Uttar Pradesh, India.

Dr. Ashwani Kumar Goyal, Joint Sectary Higher Education, U.P Civil Secretariat, Lucknow, Uttar Pradesh, India. 